\title{
COMPARATIVE STUDY SPOC VS. MOOC FOR SOCIO-TECHNICAL CONTENTS FROM USABILITY AND USER SATISFACTION
}

\author{
Giovani Lemos de CARVALHO JUNIOR \\ ORCID: 0000-0002-6041-1552 \\ Faculty of Education Sciences, Vigo University \\ Vigo, Spain \\ Dr. Daniel Cebrian ROBLES \\ ORCID:0000-0002-3768-1511 \\ Faculty of Education Sciences, Malaga University \\ Malaga, Spain \\ Dr. Manuel Cebrian de la SERNA \\ ORCID: 0000-0002-0246-7398 \\ Faculty of Education Sciences, Malaga University \\ Malaga, Spain \\ Dr. Manuela Raposo RIVAS \\ ORCID: 0000-0001-7781-7818 \\ Faculty of Education Sciences, Vigo University \\ Vigo, Spain
}

Received: 11/10/2018 Accepted: 02/11/2018

\begin{abstract}
According to literature, usability and user satisfaction directly influence learning achievement. However, few studies address those elements in MOOCs (massive open online courses). Relevant questions such as "Are drop-out rates similar between SPOCs (small private open courses) and MOOCs?" and "Are there significant usability and satisfaction differences between both formats?" may help improve initiatives and dissemination policies regarding open knowledge. This study aims to upgrade guidelines for the conversion of SPOCs into MOOCs, by exploring usability and satisfaction in both formats. A quantitative research based on a questionnaire was designed, and the validated SUSE (Satisfaction and Usability of Software in Education) instrument was applied to 7 courses of each type, with the same contents, and 5,192 students. The results revealed validity and reliability, with higher satisfaction scores on the open platform. Genders, regions of residence, and age groups also provided interesting findings: students are predominantly male, young, and from diverse geographic locations. Women, the younger, and residents of economically disadvantaged regions evaluated their experiences more positively. Both formats present significantly lower dropout rates $(47.50 \%$ in MOOCs and $36.94 \%$ in SPOCs) and higher completion rates $(52.50 \%$ in MOOCs and $63.06 \%$ in SPOCs) compared to those generally observed in free enrollment courses.
\end{abstract}

Keywords: MOOC, SPOC, usability, satisfaction, use studies, comparative studies.

\section{INTRODUCTION}

The MOOCs were first seen in 2008, but became popular three years later (Bozkurt, Akgun-Özbek, \& Zawacki-Richter, 2017), with the explosion of the MOOC movement. More than half a decade after that, the expressive growth in the supply of MOOC courses continues to be a reality (Read, Barcena \& Sedano, 2018; Whitehill, Mohan, Rosen, Seaton \& Tingley, 2017). According to Shah (2018), in 2017 about 81 
million students enrolled in 9,400 courses of this nature and over 2.000 new educational actions were launched (Online Course Report, 2017). The number of institutions providing MOOCs also continues to grow vertiginously (Cabero-Almenara \& LLorente-Cejudo, 2017), and according to the same author, more than 700 universities around the world have adhered to this format.

The high drop-out rates, however, are still a great challenge (Clow, 2013; Alraimi, Zo, \& Ciganek, 2015; Yan, Lee, \& Ko, 2017). Although many researchers propose a more contextualized perspective for the analysis of these numbers, so as not to draw hasty conclusions based on the reality of traditional courses or incorrect concepts (Koller, Ng, Do, \& Chen, 2013; LeBar, 2014; Ho et al., 2014; Reich, 2015; Jordan, 2015; Hood \& Littlejohn, 2016), it is possible to verify that one of the biggest challenges of massive open training today is related to the retention of users (Khalil \& Ebner, 2014).

The percentages of actual MOOCs certificates issued today vary between 2 and 10 percent (Alraimi et al., 2015; Reich, 2014) and given the lack of studies with more appropriate methodological approaches on the issue, little is known about the factors that may lead to this concerning scenario of evasion (Liyanagunawardena, Adams, \& Williams, 2013).

Apart from the freedom of choice enjoyed by users who join MOOCs for free and may abandon the courses later, without charge, similar to what happens with free-access television, this new educational format raises the question of how to achieve the permanence of these users, in the same way that a television channel director seeks to maintain the highest audience level possible. This context presents the opportunity to discuss the problem of evasion- as in the example of free-access television production-from another approach and strategy, that addresses the peculiar elements of MOOC programs, specifically: course design, system (platform) interaction, content design, different needs and profiles of the audience, etc. In other words, get to know the final users along with other elements such as: satisfaction, interest and ease of use of these programs in the MOOC format.

The MOOC courses are offered through different educational interfaces, based on computer systems, which represent an important element with undeniable influence in learning experiences (Harrati, Bouchrikab, Taria, \& Ladjailiab, 2016; Stokes, Guillan, \& Braden, 2016). MOOCs, like any other technological support, have revolutionized the way we think of the educational process and, above all, how educational actions are modeled. Learning remains the same, but the context in which it occurs is very different compared to the reality of previous generations. Conole (2013) uses the term TEL (Technology Enhanced Learning), which is already disseminated among the scientific community, to define this particular context of interaction with technological resources for educational purposes.

In technology-enhanced context the users are both the recipients of educational contents and protagonists in the building process of the course, since the quality of their experience determines the effectiveness of the educational action. Elements such as accessibility, satisfaction, usability and user experience are considered key in this scenario (Petrie \& Bevan, 2009) and should be among the central concerns of educational design which should focus on the users (Hassan, Martín, \& Iazza, 2004).

Usability, defined according to ISO 9241-11 in Bevan (1998) is "the extent to which a product can be used by specified users to achieve specified goals with effectiveness, efficiency and satisfaction in a specified context of use". Usability is a variable that has a direct and strong impact on educational efficacy and the learning experience, in general (Orfanou, Tselios, \& Katsanos, 2015), specifically when applied to systems, tools and web services (Sauro, 2011). Therefore, the simpler and easier to use they are, the greater impact technological systems and web tools will have on user communication and learning processes. In this sense, studies comparing usability in different MOOC platforms with the same activities, conclude that perceived usability has an impact on student learning effectiveness (Katsanos, Tselios, \& Xenos, 2012; Yousef, Chatti, 
Schroeder \& Wosnitza, 2015, Tsironis, Katsanos, \& Xenos, 2016). These principles require that we get to know what usability these web services offer to improve the designs of the MOOC courses focused on the users. This implies a difficult task when defining what the principle of the course design should be, that takes into account the interests, objectives and needs of the users, which, similar to the previous free-access television example, we need to know their opinion in order to redefine the courses according to this knowledge.

Usability is closely related to many other variables which are identified below, such as satisfaction and utility, because if something is easy to use or if it is useful, it will provide a feeling of satisfaction to the user and vice versa. This along with accessibility, that although it tries to address the heterogeneity and diversity of users, a usable design can, paradoxically, be guided to users and concrete profiles (Hassan, Martín, \& Iazza, 2004). Thus is the case of SPOCs (Small Private Online Courses) that seek success where the MOOCs failed, guiding their design to more specific users while maintaining the general MOOC format. In addition to these, other variables were recently studied in virtual environments, such as emotional intelligence (Kumar, 2016; Loureiro \& Messias, 2016) and user engagement (Barak, Watted, \& Haick, 2016; Barba, Kennedy, \& Ainley, 2016; Ho, 2016; Rodriguez, Ramos, Silva, \& Gomes, 2016) in technology-mediated educational programs. There are studies that relate user commitment to success in programs, such as the work of Chen, Lambert, and Guidry (2010), which points out the existence of a positive relationship between the use of educational technologies, student commitment and desired learning outcomes. The "terminal efficiency" indicator, understood as the initial fraction of enrollees who successfully complete a course (Observatory of Educational Innovation, 2014), is also influenced by this variable (Aleman de la Garza, Sancho-Vinuesa, \& Gómez Zermeno, 2015). However, it is interesting to focus in depth on these analyses from the strategy of maintaining the same MOOC formats but comparing them with specific user responses. That is, to analyze the same variables between the same courses, but comparing them in the different two modalities (SPOC and MOOC).

The present study seeks to obtain answers to improve this shift that guides institutional courses (SPOC) to users in general (MOOC). There are a number of ethical and political reasons that encourage us to propose the discussion of these open courses (Farow, 2016), including the recognition by the United Nations and its Organization for Education, Science and Culture (UNESCO) that it is necessary to ensure full, equal and universal access to education, a human right of fundamental importance for the exercise of other human rights (UNESCO, 2017). This study is motivated by different technical and pedagogical reasons in order to achieve the best results regarding these objectives. We also share the same view as Teixeira, Mota, GarcíaCabot, García-Lopez, and de-Marcos (2016) when they affirm that virtual educational environments should be able to adapt to different learning contexts, to provide different types of students with unique learning experiences that also lead to quality educational processes (Daradoumis, Bassi, Xhafa, \& Caballe, 2013). Hence the need to achieve flexibility and adaptation from one format to another (SPOC to MOOC), with greater efficacy and efficiency, developing a user-centered study to differentiate both formats. We not only expect to improve the MOOC design, but also to perfect the course that is already being offered in SPOC format.

\section{METHODOLOGY}

For the purposes of the study, a quantitative method with a survey design is carried out, with a descriptive correlational approach.

\section{Research Context}

The context of the present study is the National Police Academy, a public educational institution linked to the Federal Police in Brazil, which since 2007, has been developing and executing distance learning courses in a massive way, which were at first directed only to its officials (SPOCs), supported by ICT and through 
its own virtual environments. Given the success of its corporate platform, the first in the Brazilian public service to adopt a free open-source system, and the quality of the contents offered to the users, the open platform "ANP Cidadâ" was created in 2010, offering MOOCs for the training of the community in general.The courses were initially modeled for specific and restricted audiences, and were gradually opened to the general public in MOOC format, in a social project that has already enabled the training of about 15.000 people. This initiative is a direct response to an open knowledge dissemination policy in public institutions in Brazil.

\section{Data Collection}

As we have shown in the literature review, there are reasons for a study focusing on different variables that affect users (such as usability, satisfaction, utility and learning profiles). This study focuses on the variables of usability and satisfaction of users as the clearest indicators of platform quality, comparatively analyzing results obtained from the application of the SUSE (Satisfaction and Usability of Software Education) instrument to both course formats offered by the National Police Academy: SPOC and MOOC. SUSE is a questionnaire that is validated with a value of 0.81 and a reliability of 0.78 in the usability and 0.90 in the satisfaction (Serrano-Angulo \& Cebrian-Robles, 2012) and designed specifically for virtual educational environments (Serrano-Angulo \& Cebrian-Robles, 2014; Monedero-Moya, Cebrian-Robles, \& Desenne, 2015). The instrument presents a Cronbach Alpha coefficient of 0.91 with the results obtained in the sample of MOOCs and SPOCs.

The questionnaire consists of 35 items to be assessed on a Likert scale from 1 to 5 . These items are listed directly ( 1 the worst to 5 the best) and indirectly ( 1 the best to 5 the worst). There are 25 items (11 direct and 14 indirect) concerning usability, and 10 (6 direct and 4 indirect) related to satisfaction. The order of the items is random to avoid answers without prior reading.

We are convinced that the variables of satisfaction and usability influence, and in some way, reflect the educational results, together with the knowledge to better understand the levels of abandonment in a MOOC; at the same time, they could help to redefine and redesign the contents in the process of transformation of SPOCs into MOOCs.

\section{Research Questions and Hypotheses}

Therefore, the following research questions (RQ) should be asked:

RQ-1) If the contents and the platform used in the two SPOC and MOOC modalities are the same, will there be the same level of abandonment in both cases?

RQ-2) Are there significant differences in usability and satisfaction among users of both modalities?

RQ-3) Is there a correlation between elements of the user profile and the perception regarding usability and satisfaction?

In addition to answering these questions, the objective of the present study is to get to know the profile of people who attend this kind of course, in a more specific context: offered in Portuguese language and through an open platform. For that reason, the study variables are the following: first, the users' responses concerning Usability and Satisfaction; second, the formats offered (SPOC and MOOC); and thirdly, the variables of the user's profile (gender, region of residence and age).

The hypotheses that motivated the present study are the following:

$\mathrm{H}-1)$ Even if the same contents and learning environments are maintained, there may be differences in dropout rates between MOOC and SPOC modalities;

H-2) There may exist significant differences in usability and satisfaction measured from users of both formats; 
H-3) Elements of the user profile, such as age, gender, and geographic location may influence their perception regarding usability and satisfaction in both MOOC and SPOC formats.

\section{Sample and Data Analysis}

Currently, the institution has approximately 28,000 students enrolled in nearly 170 courses in both formats (SPOC and MOOC), in two different platforms: one closed, and exclusive for the officials of this institution (SPOC), and another, open to the general public (MOOC). Together the two platforms have more than 30,000 registered users. Forty-three courses were executed in the second quarter of 2016: 8 MOOCs and 35 SPOCs, with a total of 9.401 enrolled students (6.813 on the closed platform and 2.588 on the open platform). In this scenario, a comparative analysis was performed between 7 courses available in both formats, with 5.192 enrolled students (2.604 on the closed platform and 2.588 on the open platform).

The study population is composed of all students enrolled in the 14 analyzed courses ( 7 of each format). To answer two initial research questions, the entire population was considered. For the third research question, the SUSE instrument was applied to a sample of 750 students who answered the questionnaire (398 from the SPOCs and 352 from the MOOCs). The questionnaire was answered anonymously, and the data from the students enrolled in all the courses and in both of the modalities were presented, with three different categories: gender, age and geographical location. The data obtained were analyzed, using the IBM SPSS 23.0 software. A descriptive, exploratory and a contrast of hypothesis analysis is carried out, with nonparametric tests applied to two independent samples, because of the non-normal distribution of the results calculated by the Kolmogorov-Smirnov Normality Tests for Statistical Analysis.

\section{RESULTS}

The results of the first research question (RQ1) is shown in tables 1 and 2, where the data resulting from the 7 courses is presented, regarding enrollment, terminal efficiency, abandonment, success and failure in both formats.

Table 1. MOOC data (open platform)

\begin{tabular}{|c|c|c|c|c|c|}
\hline Course number & Enrolled students & Terminal efficiency & Abandonment & Success & Failure \\
\hline 1 & 1.085 & $\begin{array}{c}667 \\
(61.47 \%)\end{array}$ & $\begin{array}{c}418 \\
(38.53 \%)\end{array}$ & $\begin{array}{c}627 \\
(57.79 \%)\end{array}$ & $\begin{array}{c}40 \\
(3.69 \%)\end{array}$ \\
\hline 2 & 195 & $\begin{array}{c}108 \\
(55.38 \%)\end{array}$ & $\begin{array}{c}87 \\
(44.62 \%)\end{array}$ & $\begin{array}{c}76 \\
(38.97 \%)\end{array}$ & $\begin{array}{c}32 \\
(16.41 \%)\end{array}$ \\
\hline 3 & 207 & $\begin{array}{c}80 \\
(38.65 \%)\end{array}$ & $\begin{array}{c}127 \\
(61.35 \%)\end{array}$ & $\begin{array}{c}68 \\
(32.85 \%)\end{array}$ & $\begin{array}{c}12 \\
(5.8 \%)\end{array}$ \\
\hline 4 & 294 & $\begin{array}{c}111 \\
(37.76 \%)\end{array}$ & $\begin{array}{c}183 \\
(62.24 \%)\end{array}$ & $\begin{array}{c}87 \\
(29.59 \%)\end{array}$ & $\begin{array}{c}24 \\
(8.16 \%)\end{array}$ \\
\hline 5 & 220 & $\begin{array}{c}130 \\
(59.09 \%)\end{array}$ & $\begin{array}{c}90 \\
(40.91 \%)\end{array}$ & $\begin{array}{c}125 \\
(56.82 \%)\end{array}$ & $\begin{array}{c}5 \\
(2.27 \%)\end{array}$ \\
\hline 6 & 92 & $\begin{array}{c}58 \\
(63.04 \%)\end{array}$ & $\begin{array}{c}34 \\
(36.96 \%)\end{array}$ & $\begin{array}{c}49 \\
(53.26 \%)\end{array}$ & $\begin{array}{c}9 \\
(9.78 \%)\end{array}$ \\
\hline 7 & 495 & $\begin{array}{c}258 \\
(52.12 \%)\end{array}$ & $\begin{array}{c}237 \\
(47.88 \%)\end{array}$ & $\begin{array}{c}252 \\
(50.91 \%)\end{array}$ & $\begin{array}{c}6 \\
(1.21 \%)\end{array}$ \\
\hline & Averages & $52.50 \%$ & $47.50 \%$ & $45.74 \%$ & $6.76 \%$ \\
\hline
\end{tabular}


As shown in Tables 1 and 2, the median levels of abandonment and terminal efficiency presented by the MOOCs are significantly different $(p<.05)$ in relation to the SPOCs where abandonment cases are lower, $(\chi 2=60.3669, p<.00001)$. Even with this evidence, it is possible to observe that the dropout rates in MOOCs here are well below what is normally found in the modality: between 1 and $10 \%$ of completion (Alraimi et al., 2015; Reich, 2014).

Table 2. SPOC data (closed platform)

\begin{tabular}{cccccc}
\hline Course number & Enrolled students & Terminal efficiency & Abandonment & Success & Fracaso \\
\hline 1 & 1.795 & 1.173 & 622 & 1.153 & 19 \\
& & $(65.35 \%)$ & $(34.65 \%)$ & $(64.23 \%)$ & $(1.06 \%)$ \\
2 & 92 & 74 & 18 & 69 & 5 \\
& & $(80.43 \%)$ & $(19.57 \%)$ & $(75 \%)$ & $(5.43 \%)$ \\
3 & 44 & 20 & 24 & 20 & 0 \\
& & $(45.45 \%)$ & $(54.55 \%)$ & $(45.45 \%)$ & $(0 \%)$ \\
4 & 76 & 40 & 36 & 38 & 2 \\
& & $(52.63 \%)$ & $(47.37 \%)$ & $(50 \%)$ & $(2.63 \%)$ \\
5 & 171 & 142 & 29 & 140 & 2 \\
& & $(83.04 \%)$ & $(16.96 \%)$ & $(81.87 \%)$ & $(1.17 \%)$ \\
6 & 221 & 169 & 52 & 162 & 7 \\
& & $(76.47 \%)$ & $(23.53 \%)$ & $(73.3 \%)$ & $(3.17 \%)$ \\
7 & \multirow{2}{*}{205} & 78 & 127 & 77 & 1 \\
& \multirow{2}{*}{20} & $(38.05 \%)$ & $(61.95 \%)$ & $(37.56 \%)$ & $(0.49 \%)$ \\
& \multirow{2}{*}{ Averages } & $63.06 \%$ & $36.94 \%$ & $61.06 \%$ & $1.99 \%$ \\
\hline
\end{tabular}

The comparison of the usability and satisfaction (RQ2) between the questionnaire responses on both platforms does not show any significant difference between students enrolled in SPOC (398 or 15.28\% of the 2.588 answered) and those enrolled in MOOC (352 or $13.60 \%$ of the 2.604 answered). The slightly higher number of respondents in the closed platform is probably due to professional requirements for the certification obtained in the courses.

\section{Genders}

The results of the application of the SUSE instrument were analyzed and compared in the 7 courses of the sample available in both formats. The users were different in both of the modalities (SPOC and MOOC), representing in both cases 474 men $(63.20 \%)$ and 276 women $(36.80 \%)$. In both platforms the gender distribution (RQ3) shows the predominance of men $(60.80 \%$ in the closed and $65.90 \%$ in the open platform) in relation to women (39.20\% in closed and 34.09\% in open platform).

User gender data was crossed in the open and closed courses to verify the existence of significant differences between men and women when choosing a course in MOOC or SPOC format. The results confirmed these differences: the number of women who preferred to use the open platform (MOOC) was significantly higher than the men, $(\chi 2=21, p<.05)$. 


\section{Genders: Usability and Satisfaction}

Both female and male genders do not present a normal curve of usability and satisfaction according to Kolmogorov-Smirnov. The Mann-Whitney $U$ test for the two independent samples results with a median of 80 in men and 75 in women for usability, and 77 in men and 75 in women for satisfaction. Higher male scores were observed, and was significantly higher than the female gender for usability $(\mathrm{U}=331, p=.000)$ and for satisfaction $(\mathrm{U}=360, p=.001)$.

Regions of residence

As a result of the Kruskal-Wallis test (for $\mathrm{k}$ samples) it is possible to conclude that there are significant differences between the different medians obtained in the different states of Brazil with a $(\chi 2=80.969, p=$ $.000)$ for usability and $(\chi 2=81.580, p=.000)$ for satisfaction. This significant difference in the medians exists in practically all combinations after applying the Dunn's test.

Table 3. Brazilian regions of residence of the respondents

\begin{tabular}{llllll}
\hline \multirow{2}{*}{ Platform } & \multicolumn{3}{l}{ Country region } & & \\
\cline { 2 - 6 } & Midwest & North & Northeast & South & Southeast \\
\cline { 2 - 6 } Open & 105 & 28 & 64 & 55 & 100 \\
& $(29.83 \%)$ & $(7.95 \%)$ & $(18.18 \%)$ & $(15.63 \%)$ & $(28.41 \%)$ \\
\multirow{2}{*}{ Closed } & 149 & 69 & 40 & 71 & 69 \\
& $(37.44 \%)$ & $(17.34 \%)$ & $(10.05 \%)$ & $(17.84 \%)$ & $(17.34 \%)$ \\
\hline
\end{tabular}

In both platforms, there is a high concentration of users from the Midwest, the smallest of the Brazilian regions. These figures are justified because the capital of the country is in this region, which concentrates the main government bodies and, thus, most of the public officials who, for various reasons, arrive at the platforms of the Federal Police.

As for the other regions, while the closed platform reproduces the concentration of civil servants in the decentralized units of the Federal Police, distributed throughout the country, the origin of the users in the open platform reflects the distribution of the population in Brazil which, by itself, already represents a positive result: the open courses manage to reach all corners of the country, favoring and offering, in a fair way, training opportunities to the population as a whole.

\section{Regions of Residence: Usability and Satisfaction}

A study made with Kruskal-Wallis for different regions (RQ3) showed significant differences for usability and satisfaction on open and closed platforms. In both contexts and variables, the regions that stood out were, precisely, the least economically favored in the country: North and Northeast.

For usability, the results point to significant differences between the MOOC $(\chi 2=16.18, p=.003)$ and SPOC $(\chi 2=13.94, p=.007)$ platforms, being that the Northeast region, with a median of 88.33 , was the one that presented greater usability on the MOOC platform and the North region, with a median of 78.54, on the SPOC platform.

As for satisfaction, there are also significant differences between the MOOC $(\chi 2=11.10, p=.025)$ and the SPOC platforms $(\chi 2=10.66, p=.031)$, being that the Northeast region, with a median of 85.22 , was the one that presented greater usability on the MOOC platform and the North region, with an median of 77.70, with higher results on the SPOC platform. 
It is possible that the numbers obtained with the users coming from the less favored regions of Brazil are influenced by the sensation generated in them from the inherent opportunity brought through the open courses. In the case of MOOCs, they are free learning experiences that reach audiences that would be unreachable through other formats. In the case of SPOCs, the same sensation can arise in the users reached less frequently by the educational actions that are traditionally promoted by the institution.

\section{Age Groups}

As for age (RQ3), the sample has been divided into three groups that are approximately separated by quartiles 25, 50 and 75 (less than 30, between 31 and 40, and over 40 years old). The Kruskal-Wallis test (for k samples) was applied and the results show significant dissimilarities between the different medians obtained by the Chi-square age groups, which is $(\chi 2=34.510, p=.000)$ for usability and $(\chi 2=8.860, \mathrm{p}=.012)$ for satisfaction. It is possible to notice that the difference is even greater in the score median of usability and user satisfaction in the second age group (between 31 and 40 years old) compared to the third group (over 40 years old). For both usability and satisfaction, there is a median of 81.7 and 75.0 for usability, and 77.3 and 75.0 for satisfaction in the second group compared to third, respectively.

In the closed platform, from which come 398 (53.07\%) of the respondents, $212(53.27 \%)$ of the users are over 40 years old. The group from 31 to 40 years old sums $123(30.90 \%)$ students and, finally, the younger group (under 30 years old) consists of only $63(15.83 \%)$ users. The scenario of the open platform is very different: the most representative group (180 students or $51.14 \%$ ) is also the youngest, followed by the intermediate group (120 students or 34.09\%) and, finally, the older group (over 40 years old), with only 52 $(14.77 \%)$ individuals within the analyzed sample.

Two aspects stand out in the analysis of the results of the investigation by age group: the predominance of responses obtained from the closed platform, who were more critical, even by the way through which the users access the courses (often involuntarily). The second aspect are the divergent perceptions of the different generations: in the group of people over 40 we have the baby boomers, and some representatives of the socalled "Generation X". In the intermediate group there are individuals of the generations X and Y. Lastly, in the younger and less representative group, users of the $\mathrm{Y}$ and $\mathrm{Z}$ generations. The perception of older users in relation to new technologies is generally different compared to younger users (Canas-Bajo, Leikas, Jokinen, Canas, \& Saariluoma, 2016; Ivanova \& Smirkarov, 2009).

\section{Age Groups: Platforms}

Age data from the samples has been crossed with the platform to check if there are significant differences between the distinct groups when choosing the platform. The results of the application of the Chi-square test show significant differences between age groups when deciding whether to use the MOOC or the SPOC platform. There is also a significant difference between the youngest group, who prefer to use the open platform, compared to those over 40 , who do not prefer them $(\chi 2=120, p<.05)$.

The age concentration of students on the closed platform obviously reflects the profile of officials, which is also determined by the activity they perform. As for the results obtained on the open platform, they reflect the tendency which has already been verified in other contexts (Cole \& Timmerman, 2015; Emanuel, 2013; Palin, 2014) in which the majority of MOOC students are young, well-educated men looking for looking for new skills to advance their careers. 


\section{Age Groups: Usability and Satisfaction}

Table 4. Differences according to age group and the variables of usability and satisfaction

\begin{tabular}{lll}
\hline Medians & Usability & Satisfaction \\
\hline Under 30 years old & 80.0 & 77.3 \\
Between 31 and 40 years old & 81.7 & 77.3 \\
Over 40 years old & 75.0 & 75.0 \\
\hline
\end{tabular}

Two factors may justify the difference in scores between the age groups. The first is related to the significant number of users over 40 on the closed platform. Students coming from the closed platform get to the courses for distinct reasons in relation to those who use the open platform and so they tend to be more critical in relation to the whole educational context. Often, as we have already discussed, course attendance is due to institutional demands and is a professional requirement, i.e. not voluntary, the opposite of what happens on the open platform. Another factor with possible influence on the numbers obtained is the contrast of technology perception observed in different age groups. While the younger users are generally more accustomed to interacting with computerized systems, the older ones tend to see them with more reservations.

\section{Comparative Analysis of Formats According to Usability and Satisfaction Variables}

The Mann-Whitney U statistic for two independent samples does not result in significant differences in the medians of the usability scores in the samples of groups using the open and the closed platform $(U=302, p$ $=.640)$. However, there were significant differences in the median scores of higher satisfaction obtained in groups using the open platform with a median of 79.54 versus $75.00(\mathrm{U}=276, p=.005)$ on the closed platform.

Undoubtedly, the verified difference is related to the reason that leads users to the open platform: a genuine interest in learning. The institutional platform is more susceptible to criticism and the receptivity of the courses is certainly higher in the public that has chosen to enroll for reasons not related to the institution. The contrast may be even greater among specific courses, since some of them are linked professional requirements "imposed" and required from the officials.

Based on the results obtained from the general comparison of variables and formats in all courses, a significantly greater satisfaction is perceived among MOOC users compared to SPOC users, most likely as a consequence of the freedom of choice that the former have. While the MOOC audience gets to the courses voluntarily, influenced by a number of personal and professional factors, the institutional users who attend the SPOCs are usually indicated or participate due to professional demands.

\section{Comparative Analysis According to Each Course}

Next, a data analysis on each of the 7 courses was performed. The available data and results may be seen in Table 5. A deeper and more detailed analysis will be carried out only in the courses with significant results. 
Table 5. Comparative analysis between SPOCs and MOOCs by courses

\begin{tabular}{|c|c|c|c|c|}
\hline $\begin{array}{l}\text { Course } \\
\text { number }\end{array}$ & $\begin{array}{l}\text { MOOC } \\
\text { respondents }\end{array}$ & $\begin{array}{l}\text { SPOC } \\
\text { respondents }\end{array}$ & $\begin{array}{l}\text { Total of } \\
\text { respondents }\end{array}$ & Results \\
\hline 1 & $\begin{array}{c}41 \\
(50 \%)\end{array}$ & $\begin{array}{c}236 \\
(58,27 \%)\end{array}$ & 277 & $\begin{array}{l}\text { There are no differences in terms of satisfaction }(U=8056 \text {, } \\
p=.624) \text { and usability }(U=7526.5, p=.194) .\end{array}$ \\
\hline 2 & $\begin{array}{c}41 \\
(66,13 \%)\end{array}$ & $\begin{array}{c}21 \\
(33,87 \%)\end{array}$ & 62 & $\begin{array}{l}\text { There are no differences in terms of usability }(U=428 \text {, } \\
p=.970) \text { and satisfaction }(U=392, p=.562) \text {. }\end{array}$ \\
\hline 3 & $\begin{array}{c}71 \\
(89,87 \%)\end{array}$ & $\begin{array}{c}8 \\
(10,13 \%)\end{array}$ & 79 & $\begin{array}{l}\text { There are no differences in terms of usability }(U=69 \text {, } \\
p=.107) \text {. } \\
\text { However, there are significant differences regarding } \\
\text { satisfaction }(U=49, p=.015) \text {. }\end{array}$ \\
\hline 4 & $\begin{array}{c}44 \\
(74,58 \%)\end{array}$ & $\begin{array}{c}15 \\
(25,42 \%)\end{array}$ & 59 & $\begin{array}{l}\text { There are no differences in terms of usability }(U=320 \text {, } \\
p=.868) \text { and satisfaction }(U=261, p=.232) .\end{array}$ \\
\hline 5 & $\begin{array}{c}50 \\
(52,08 \%)\end{array}$ & $\begin{array}{c}46 \\
(47,92 \%)\end{array}$ & 96 & $\begin{array}{l}\text { There are no differences in terms of usability }(U=1022 \text {, } \\
p=.347) \text { and satisfaction }(U=1085, p=.635) \text {. }\end{array}$ \\
\hline 6 & $\begin{array}{c}23 \\
(31,51 \%)\end{array}$ & $\begin{array}{c}50 \\
(68,49 \%)\end{array}$ & 73 & $\begin{array}{l}\text { There are significant differences for both usability }(U=306 \text {, } \\
p=.001) \text { and satisfaction }(U=361, p=.011) \text {. }\end{array}$ \\
\hline 7 & $\begin{array}{c}82 \\
(78,85 \%)\end{array}$ & $\begin{array}{c}22 \\
(21,15 \%)\end{array}$ & 104 & $\begin{array}{l}\text { There are no differences in terms of usability }(U=784 \text {, } \\
p=.084) \text { and satisfaction }(U=891, p=.315) \text {. }\end{array}$ \\
\hline
\end{tabular}

\section{Course No. 3}

The results of the analysis of this course on the two platforms (MOOC and SPOC) do not fit a normal curve when the Kolmogorov-Smirnov test is applied to usability and satisfaction data. Therefore, we used the Mann-Whitney $U$ test for two independent samples, which resulted in no difference in the medians of usability scores in the sample of groups using the open and the closed platforms $(U=69, p=.107)$. However, there were significant differences in the median, with higher satisfaction scores obtained by groups using the open platform with a score of 89.77 versus $73.86(\mathrm{U}=49, p=.015)$ on the closed platform.

\section{Course No. 6}

If we analyze this course on both platforms it is possible to notice that it does not fit a normal curve when the Kolmogorov-Smirnov test is applied to usability and satisfaction data. Therefore, we used the MannWhitney $U$ test for two independent samples, which resulted in significant differences in the medians of usability scores in the samples of groups using the open and the closed platforms, demonstrating a lower score (63.33) for MOOCs compared to the result (76.66) obtained in SPOCs $(\mathrm{U}=306, p=.001)$. There are also significant differences in the median satisfaction scores in the group using the open platform, being lower in the cases with a score of 70.45 , in relation to the group using the closed platform, which presents a score of $77.27(\mathrm{U}=361, p=.011)$.

\section{DISCUSSIONS AND CONCLUSION}

The first finding that stands out in the sample analyzed by this study are the low dropout rates $(47.50 \%$ in the case of MOOCs and $36.94 \%$ in the case of SPOCs) and the high terminal efficiency levels $(52.50 \%$ in the MOOCs and $63.06 \%$ in the SPOCs). In some of the compared courses, the difference found between the platforms is also reflected in the results obtained from the application of the SUSE instrument: open platform users tend to present higher satisfaction levels compared to those from the closed platform. Hence, it may be concluded that usability and satisfaction can positively influence the completion rates of the courses. Among the variables possibly involved in the low levels of abandonment, we may highlight the 
quality of educational design and the institutional credibility of the Federal Police among Brazilians. It is also important to emphasize the monitoring of courses and students which is carried out by the supervisor, a professional who acts in each course promoted by the National Police Academy, answering questions, answering questions and encouraging participation.

The reliability results of the SUSE instrument translated into Portuguese were high (0.91) and had large samples, coinciding with other studies where the same instrument was translated to Greek, and compared to different learning management systems and with small samples (Orfanou, Tselios, \& Katsanos, 2015).

If we focus on the user, usability is one of the dimensions that has been found to influence the effectiveness of MOOCs (Gamage, Fernando, \& Perera, 2015). Despite this, the same dimension of usability is closely related to satisfaction, as we can see in this study when we find a correlation of variables of 0.76 .

The contrast in the scores obtained in usability and satisfaction from male and female users could be explained by the differences in relation to what each gender judges as attractive, as some studies have already shown (Djamasbi et al., 2007). Science has also shown that men and women process signals derived from the same stimuli differently (Kimura, 1992; Gregory, 1998) and that aesthetic opinions and preferences are influenced by gender (Moss, Gunn, \& Heller, 2006; Tedesco, Chadwick-Dias, \& Tullis 2004). Lin \& Hsieh (2016), in a study on website interface design, proposed the three most important criteria for men (compatibility, minimal action and flexibility) and women (compatibility, learning possibilities and user orientation).

Some studies on participation profiles in MOOC courses - such as those conducted by Christensen et al. (2013) - have come to the conclusion that students tend to be young, well educated, employed, and from developed countries. The analysis of the sample showed that, in fact, those under 30 years of age have absolute predominance in the courses, followed by those between 30 and 40 years old, which corroborates this conclusion. Data such as educational level and employment situation were not included, so we expect future works to have a broader profile.

As for the origin (region of residence) of students, in the case of open courses, it seems to coincide, more or less, with the geographical distribution of the country, including states and regions that are less economically favored, which seems to contrast with the conclusion drawn by the aforementioned studies (Christensen et al., 2013; Garrido et al., 2016; Glass, Shiokawa-Baklan, \& Saltarelli, 2016), which pointed out to the predominance of students from developed regions.

As indicated in the cited references, all these variables (usability, satisfaction, accessibility, utility, emotional intelligence and commitment) have been studied in technology-mediated contexts, especially virtual learning environments and more recently in MOOC platforms. There is still much to analyze about these variables in MOOCs, using different methodologies and qualitative and quantitative study approaches. For future work we hope to be able to expand personal variables, to precisely locate users to know exactly where they come from (towns or villages, small or large cities, countryside, mountains or seaside, zones or states, etc.), in order to have a precise map to implement measures and policies for educational inclusion.

Authors' Note: This article is part of a $\mathrm{PhD}$ thesis on the comparison between small private open courses (SPOCs) and massive open online courses (MOOCs), supported by the Ministry of Justice of Brazil and developed under the interuniversity doctoral program "Equity and Innovation in Education", promoted by the Universities of A Coruna, Cantabria, Oviedo, Santiago and Vigo. 


\section{BIODATA and CONTACT ADDRESSES of AUTHORS}

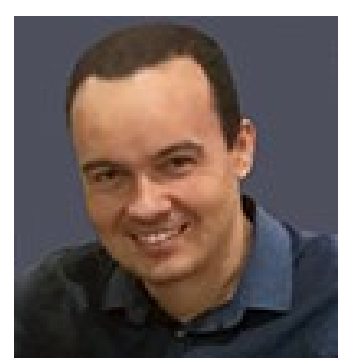

Giovani Lemos de CARVALHO JUNIOR is a PhD student at the University of Vigo in the interuniversity program "Equity and Innovation in Education". Currently, his research lines are: innovation for educational equity; and processes of inclusion and socio-educational exclusion. He is also a researcher and professor at the National Police Academy, the Higher School of Police and the National School of Public Administration, in Brazil. In charge of the educational technology team and administrator of institutional digital learning environments. Instructional designer, content maker, tutor, and supervisor of several online courses. Master in New Technologies applied to Education by the University of Malaga (Spain). Expert in Brazilian Public Law and graduated in Social and Legal Sciences by the University of Ribeirão Preto (Brazil).

Giovani Lemos de CARVALHO JUNIOR

Faculty of Education and Sport Sciences. Vigo University

Address: Campus A Xunqueira, 36005 Pontevedra, Spain, Spain

Phone: $+55612024-8925$

E-mail: giojr@uvigo.es

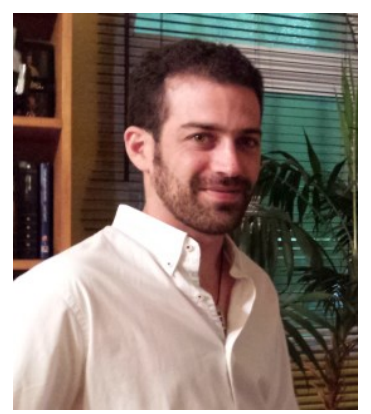

Daniel Cebrian ROBLES is an Industrial Engineer and Lecturer in the Department of Mathematics, Social and Experimental Science Education at Malaga University, in Spain. He wrote his first $\mathrm{PhD}$ thesis about the optimization of a device to extract the energy of the tides and his second $\mathrm{PhD}$ thesis is about an instrument to measure the usability and satisfaction in educational tools. Currently, his research focuses on the argumentation processes in science education and how new technologies and methodologies may help. He is also interested in improving the scientific and technological knowledge of students and is part of ENCIC research group (Grupo de Investigación en Ensenanza de las Ciencias y Competencias). He has created new tools for improving teaching and learning processes such as CoRubric, Open Video Annotation (OVA), and - more recently CoAnnotation which has been improved the last version of OVA. He was a Visiting Fellow at MIT's HyperStudio - Center for Digital Humanities in 2016 for that purpose and a Visiting Fellow at Harvard University in 2013-14 for a research related to annotations technologies for education. He is involved in different international project as lelenet.net to create schools' networking and STEAM projects to connect the robots in schools. http://danielcebrian.com

\section{Daniel Cebrian ROBLES}

Department of Education Sciences. Faculty of Education Sciences.

Address: Bulevar Louis Pasteur, 25 - Malaga University, 20730, Malaga, Spain

Phone: +34 619013012

E-mail: dcebrian@uma.es

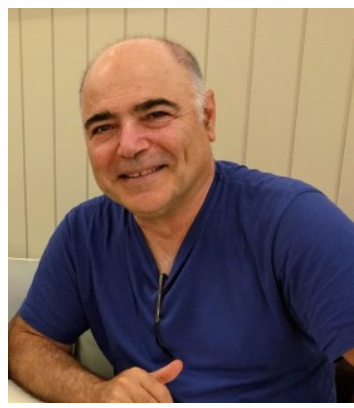

Manuel Cebrian de la SERNA is a Ph.D. Professor at Malaga University, in Spain. His research lines are: a) educational innovation vs technological innovation; B) University teaching c) Practicum. He has been director of several services of training of university teachers (ICE, Educational Innovation Service, Virtual Teaching). Decorated with the "Order of Puerto Ayacucho" for the projects developed in Amazonas (Venezuela) http://amazonas.uma.es. Director of the research group Gtea (http://gtea.uma.es). He has been an adviser to the Distance Education System (SINED) and the Rectors' Association (ANUIES) in Mexico. External evaluator in several evaluation agencies, such as ANEP, Castilla y León. Editor of Practicum Journal -REP- [http://revistapracticum.com]. 
Director of the research group, Junta de Andalucía (SEJ-462): Globalization, Technology, Education and Learning (Gtea) (http://gtea.uma.es). Actually Director of the R+D+i projects: Study of the impact of federated erubricas in evaluating the competences in the practicum [http://erubrica.org/] and the Vidanet project (Video Annotation Network) https:/goo.gl/RInMGm [+] http://http://gtea.uma.es/mcebrian

\section{Manuel Cebrian de la SERNA}

Department of Didactics and School Organization. Faculty of Education Sciences.

Address: Bulevar Louis Pasteur, 25 - Malaga University, 20730, Malaga, Spain

Phone: +34 952131072

E-mail: mcebrian@uma.es

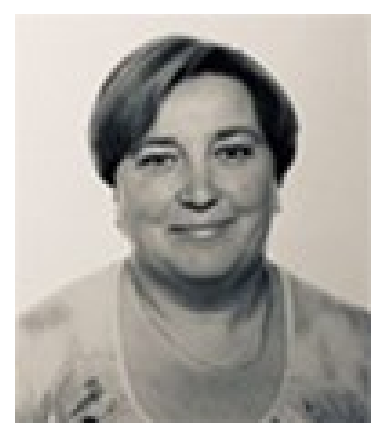

Manuela Raposo RIVAS is full Professor of New Technologies applied to Education at the University of Vigo (Spain). Doctor Raposo obtained her PhD in Education Sciences in July, 2002. Her academic interest areas and thematic research lines are: the didactical use of the information and communication technologies; the practicum in preservice teacher education; and the quality and innovation in education. On this last subject, she has over 10 journal articles published in international indexes and other national and international articles and papers submitted to international meetings. She participates in different research projects and research networks on national and regional issues. She belongs to Scientific Committees of different journals indexed in the field of Education and ICT.

\section{Manuela Raposo RIVAS}

Department of Didactics, School Organization and Research Methods. Faculty of Education Sciences. Address: Vigo University - Campus As Lagoas, 32002, Ourense, Espana

Phone: +34 988387164

E-mail: mraposo@uvigo.es

\section{REFERENCES}

Aleman de la Garza, L. Y., Sancho-Vinuesa, T., \& Gómez Zermeno, M. G. (2015). Atypical: Analysis of a massive open online course (MOOC) with a terminal efficiency of $22.35 \%$. Global Education Review, 2(3). 68-81. Retrieved from: http://ger.mercy.edu/index.php/ger/article/view/127

Alraimi, K. M., Zo, H., \& Ciganek, A. P. (2015) Understanding the MOOCs continuance: the role of openness and reputation. Computers \& Education, 80, 28-38. https://doi.org/10.1016/j.compedu.2014.08.006

Barak, M., Watted, A., \& Haick, H. (2016) Motivation to learn in massive open online courses: Examining aspects of language and social engagement. Computers \& Education, 94, 49-60. https://doi.org/10.1016/j.compedu.2015.11.010

Barba, P. G., Kennedy, G. E., \& Ainley, M. D. (2016). The role of students' motivation and participation in predicting performance in a MOOC. Journal of Computer Assisted Learning, 32(3), 218-231. https://doi.org/10.1111/jcal.12130

Bevan, N. (1998). Quality and usability: A new framework. In Van-Veenendaal, E. \& MCMullan, J. (Eds.), Achieving Software Product Quality. Netherlands: Tutein Nolthenius, 25-34. Retrieved from: https://goo.gl/Jtb71V 
Bozkurt, A., Akgun-Ozbek, E., \& Zawacki-Richter, O. (2017). Trends and Patterns in Massive Open Online Courses: Review and Content Analysis of Research on MOOCs (2008-2015). International Review of Research in Open and Distributed Learning, 18(5), 118-147. https://doi.org/10.19173/irrodl.v18i5.3080

Canas-Bajo, J., Leikas, J., Jokinen, J., Canas, J. J., \& Saariluoma, P. (2016). How older and younger people see technology in Northern and Southern Europe: Closing the generation gap. Gerontechnology 2016, 14(2), 110-117, https://doi.org/10.4017/gt.2016.14.2.010.00

Cabero-Almenara, J., \& Llorente-Cejudo, M.d.C. (2017). Los MOOC: encontrando su camino. @tic. Revista d'innovació educativa, 18, 24-30. https://doi.org/10.7203/attic.18.9928

Chen, P.-S. D., Lambert, A. D., \& Guidry, K. R. (2010). Engaging online learners: The impact of Webbased learning technology on college student engagement. Computers \& Education, 54(4), 12221232. https://doi.org/10.1016/j.compedu.2009.11.008

Christensen, G., Steinmetz, A., Alcorn, B., Bennett, A., Woods, D., \& Emanuel, E. J. (2013). The MOOC phenomenon: Who takes massive open online courses and why? SSRN Electronic Journal. (November 6, 2013). https://doi.org/10.2139/ssrn.2350964

Clow, D. (2013). MOOCs and the funnel of participation. In: Proceedings of the third international conference on learning analytics and knowledge (LAK 2013), Leuven, Belgium, April 8-12, 185 189. https://doi.org/10.1145/2460296.2460332

Cole, A. W., \& Timmerman, C. E. (2015). What do current college students think about MOOCs? MERLOT Journal of Online Learning and Teaching, 11(2), 188-201. Retrieved from: https://goo.gl/oWTUVT

Conole, G. (2013) Designing for learning in an open world. In Spector, M. \& Lajoie, S. (Eds.), Explorations in the learning sciences, Instructional systems and performance technologies:, 4. https://doi.org/10.1007/978-1-4419-8517-0

Daradoumis, T., Bassi, R., Xhafa, F., \& Caballe, S. (2013). A review on massive e-learning (MOOC) design, delivery and assessment. In Proceedings of the 2013 Eighth International Conference on P2P, Parallel, Grid, Cloud and Internet Computing (3PGCIC), 208-213. https://doi.org/10.1109/3PGCIC.2013.37

Djamasbi, S., Tullis, T., Hsu, J., Mazuera, E., Osberg, K., \& Bosch, J. (2007). Gender preferences in web design: usability testing through eye tracking. In Proceedings of the 13th Americas Conference on Information Systems (AMCIS 2007), Keystone, Colorado, August, 1-8. Retrieved from: https://goo.gl/qCg4h7

Emanuel, E. J. (2013) MOOCs taken by educated few. Nature, 503, 342. (November 21, 2013). https://doi.org/10.1038/503342a

Gamage, D., Fernando, S., \& Perera, I. (2015). Factors leading to an effective MOOC from participants perspective. In 8th International Conference on Ubi-Media Computing, UMEDIA. Article number 7297460, 230-235. 
Garrido, M., Koepke, L., Andersen, S., Mena, A., Macapagal, M., \& Dalvit, L. (2016). An examination of MOOC usage for professional workforce development outcomes in Colombia, the Philippines, \& South Africa. Seattle: Technology \& Social Change Group, University of Washington Information School.

Glass, C. R., Shiokawa-Baklan, M. S., Saltarelli, A. J. (2016). Who takes MOOCs?: New Directions for Institutional Research. MOOCS and Higher Education: Implications for Institutional Research, 41 55 .

Gregory, R. L. (1998). Eye and brain: The psychology of seeing (5th ed.). New York, NY: Oxford University Press.

Harrati, N., Bouchrikab, I., Taria, A., \& Ladjailiab, A. (2016). Exploring user satisfaction for e-learning systems via usage-based metrics and system usability scale analysis. Computers in Human Behavior, 61, 463-471. https://doi.org/10.1016/j.chb.2016.03.051

Hassan, Y., Martín Fernandez, F. J., \& Iazza, G. (2004). Diseno web centrado en el usuario: usabilidad y arquitectura de la información. Hipertext.net, (2). Retrieved from: https://goo.gl/f8q3sG

Ho, A. D., Reich, J., Nesterko, S., Seaton, D. T., Mullaney, T., Waldo, J., \& Chuang, I. (2014). Harvard and MITx: The first year of open online courses. HarvardX and MITx Working Paper No. 1. Retrieved from: https://goo.gl/XHj6Uc

Hood, N. E., \& Littlejohn, A. (2016). MOOC Quality: The need for new measures. Journal for Learning for Development, 3(3), 28-42. https://goo.gl/djsu7x

Ivanova, A., \& Smirkarov, A. (2009). The new generations of students and the future of e-learning in higher education. In International Conjerence on $\epsilon$-Learning and the Knowledge Society - $\epsilon$ Learning'09. Berlin, Germany, August 31-September 01, 2009, 17-25. Retrieved from: https://goo.gl/CRTr5J

Jordan, K. (2015). Massive open online course completion rates revisited: Assessment, length and attrition. International Review of Research in Open and Distributed Learning, 16(3), 341-358. https://doi.org/10.13140/RG.2.1.2119.6963

Katsanos, C., Tselios, N., \& Xenos, M. (2012). Perceived usability evaluation of learning management systems: A first step towards standardization of the system usability scale in Greek. In Informatics (PCI), 16th Panhellenic Conferenct. IEEE, 302-307. https://doi.org/10.1109/PCi.2012.38

Khalil, H., \& Ebner, M. (2014). MOOCs completion rates and possible methods to improve retention A literature review. In Proceedings of World Conference on Educational Multimedia, Hypermedia and Telecommunications 2014, 1305-1313, Tampere, Finland: Association for the Advancement of Computing in Education (AACE). Retrieved from https://goo.gl/PcYAh5

Kimura, D. (1992). Sex Differences in the Brain. Scientific American, 267(3), 118-125. https://doi.org/10.1038/scientificamerican0992-118

Koller, D., Ng, A., Do, C., \& Chen, Z. (2013). Retention and intention in massive open online courses: In depth. Educause Review, 48(3), 62-63. Retrieved from: https://goo.gl/qtSmnW 
Kumar, K. (2016). Emotional intelligence and achievement motivation: A correlation study. Indian Journal of Health and Wellbeing, 7(5), 546-549. Retrieved from: https://goo.gl/yYTPZA

LeBar, M. (2014). MOOCs: Completion is not important. Forbes. (September 16, 2014). Retrieved from: https://goo.gl/2FBzNR

Lin, C. J., \& Hsieh, T-L. (2016). Exploring the design criteria of website interfaces for gender. International Journal of Industrial Ergonomics, 53, 306-311. https://doi.org/10.1016/j.ergon.2016.02.002

Liyanagunawardena, T. R., Adams, A. A., \& Williams, S. A. (2013). MOOCs: a systematic study of the published literature 2008-2012. The International Review of Research in Open and Distance Learning, 14(3), 202-227. https://doi.org/10.19173/irrodl.v14i3.1455

Loureiro, A., \& Messias, I. (2016). Competences and learning profiles of digital age's students. In Pinheiro, M. \& Simões, D. (Eds.) Handbook of Research on Engaging Digital Natives in Higher Education Settings. Hershey, PA: Information Science Reference, 171-191. https://doi.org/10.4018/978-1-5225-0039-1.ch008

Monedero-Moya, J. J., Cebrian-Robles, D., \& Desenne, P. (2015). Usability and satisfaction in multimedia annotation tools for MOOCs. Comunicar, 44, 55-62. https://doi.org/10.3916/C442015-06

Moss, G., Gunn, R., \& Heller, J. (2006). Some men like it black, some women like it pink: Consumer implications of differences in male and female website design. Journal of Consumer Behavior, 5(4), July 2006, 328-341. https://doi.org/10.1002/cb.184

Online Course Report. (2017). State of the MOOC 2017: A Year of Privatized and Open Education Growth, Retrieved from: https://goo.gl/h2t5gT

Orfanou, K., Tselios, N., \& Katsanos, C. (2015). Perceived Usability Evaluation of Learning Management Systems: Empirical Evaluation of the System Usability Scale. International Review of Research in Open and Distributed Learning, 16(2). https://doi.org/10.19173/irrodl.v16i2.195

Palin, A. (2014). MOOCs: Young students from developing countries are still in the minority. Financial Times. (March 9, 2014). Retrieved from: https://goo.gl/xEQ9t0

Petrie, H., \& Bevan, N. (2009). The evaluation of accessibility, usability and user experience. In Stepanidis, C. (Ed.) The Universal Access Handbook, CRC Press. https://doi.org/10.1201/9781420064995-c20

Read, T., Barcena, E., \& Sedano, B. (2018) Current Trends in MOOC Research and Applications. In D. Jansen; L. Konings (Eds.) The 2018 OpenupEd Trend Report on MOOCs, 10-14. Maastricht, NL: EADTU. Retrieved from https://tinyurl.com/2018OpenupEdtrendreport

Reich, J. (2014). MOOC completion and retention in the context of student intent. EDUCAUSE Review. (December 8, 2014). Retrieved from: https://goo.gl/7uVXDS

Reich, J. (2015). Rebooting MOOC research. Science, 347(6217), 34-35. https://doi.org/10.1126/science.1261627 
Rodriguez, R. L., Ramos, J. L. C., Silva, J. C. S., \& Gomes, A. S. (2016). Discovery engagement patterns MOOCs through cluster analysis. Revista IEEE America Latina, 14, 4129-4135. https://doi.org/10.1109/TLA.2016.7785943

Sauro, J. (2011). Measuring Usability with the System Usability Scale (SUS). Retrieved from: https://goo.gl/iotQ5X

Serrano-Angulo, J., \& Cebrian-Robles, D. (2012). Usabilidad de la e-rúbrica mediante cuestionarios online con limesurvey. In C. Leite \& M. Zabalza (Eds.), Ensino Superior: Inovação e qualidade na docência (pp. 467-486). Porto, Portugal: CIIE - Centro de Investigação e Intervenção Educativas.

Serrano-Angulo, J., \& Cebrian-Robles, D. (2014). Usabilidad y satisfacción de la e-Rúbrica. REDU. Revista de Docencia Universitaria, 12(1), 177-195. https//doi.org/10.4995/redu.2014.6426

Scanlon, E., McAndrew, P., \& O'Shea, T. (2015). Designing for educational technology to enhance the experience of learners in distance education: How open educational resources, learning design and MOOCs are influencing learning. Journal of Interactive Media in Education, 6(1), 1-9. https://doi.org/10.5334/jime.al

Shah, D. (2018). By the numbers: MOOCs in 2017: How has the MOOC space grown this year? Get the facts, figures, and pie charts. Retrieved from: https://goo.gl/f5Dsp5

Stokes, T. A., Guillan, D. J., \& Braden, J. P. (2016). Establishing the link between usability and student satisfaction in adaptive online learning. In Proceedings of the Human Factors and Ergonomics Society Annual Meeting, 60(1), 1976-1980. https://doi.org/10.1177/1541931213601450

Tedesco, D., Chadwick-Dias, A., \& Tullis, T. (2004). Demographic differences in preferred web site content. Aging by design presentation at Bentley College, Waltham, Massachusetts. Retrieved from: https://goo.gl/HkooJ7

Teixeira, A., Mota, J., Garcia-Cabot, A., García-Lopez, E., \& de-Marcos, L. (2016). A new competencebased approach for personalizing MOOCs in a mobile collaborative and networked environment. Revista Iberoamericana de Educación. 19(1), 143-160. https://doi.org/10.5944/ried.19.1.14578

Tsironis, A., Katsanos, C., \& Xenos, M. (2016). Comparative usability evaluation of three popular MOOC platforms. In Global Engineering Education Conference (EDUCON), 2016 IEEE (pp. 608-612). https://doi.org/10.1109/EDUCON.2016.7474613

Whitehill, J., Mohan, K., Rosen, Y., Seaton, D. T., Tingley, D. (2017). Delving deeper into MOOC student dropout prediction. CoRR, arXiv:1702.06404v1. https://doi.org/10.1145/1235

Yan, A., Lee, M. J., \& Ko, A. J. (2017). Predicting abandonment in online coding tutorials. IEEE Symposium on Visual Languages and Human-Centric Computing (VL/HCC), Raleigh.

Yousef, A. M. F., Chatti, M. A., Schroeder, U., \& Wosnitza, M. (2015). A usability evaluation of a blended MOOC environment: An experimental case study. The International Review of Research in Open and Distributed Learning, 16(2) https://doi.org/10.19173/irrodl.v16i2.2032 